\title{
Luíza Mahin e Luiz Gama: escravidão e (auto)ficção numa correspondência interceptada
}

\author{
Fabiana Carneiro da Silva*
}

\section{"Escrita do eu” e escravidão}

Durante boa parte do período que compreendeu a escravidão no Brasil, o controle da "instrução" esteve centrado nas instituições religiosas. De acordo com Klebson Oliveira (2005), autor do estudo Negros e escrita no Brasil do século XIX: sócio-história, edição filológica de documentos e estudo linguístico, foi somente a partir do Primeiro Império que surgiram algumas cátedras, sobretudo de gramática, latim, grego e francês, desvinculadas da gestão eclesiástica e destinadas aos filhos dos senhores abastados. No que se refere à alfabetização, na segunda metade do XIX, utilizando os dados indicados por Boris Fausto no livro História do Brasil, Oliveira cita:

entre os escravos, o índice de analfabetos atingia $99.9 \%$ e entre a população livre, aproximadamente, $80 \%$, subindo para mais de $86 \%$ quando consideramos as mulheres...Apurou-se ainda que somente $16.8 \%$ da população entre seis e quinze anos freqüentavam escolas. Havia apenas 12 mil alunos matriculados em colégios secundários. Entretanto, calculase que chegavam a 8.000 o número de pessoas com educação superior no país. Um abismo separava, pois, a elite letrada da grande massa de analfabetos e gente de educação rudimentar (FAusto, 1994, p. 237 apud Oliveira, 2005, p. 45).

A educação escolar dos escravizados era proibida, inclusive para forros, e os poucos senhores e padres que alfabetizavam os negros e negras estavam, portanto, infringindo as leis; nesses casos, segundo Oliveira, a aquisição da escrita poderia acontecer nas "casas grandes" por iniciativa dos senhores, em situações de trabalho, para ofícios que exigiam o letramento, ou ainda nas irmandades. ${ }^{1}$ Saber ler e

* Doutora em Teoria Literária e Literatura Comparada pela Universidade de São Paulo (USP), São Paulo, SP, Brasil. E-mail: fabicarneirodasilva@yahoo.com.br.

1 Na Bahia, para legitimar que escravos não ingressassem nas escolas, o governo da província, ao longo do século XIX, cria uma série de leis expressando esse intento (FUNCEB, 1996, 222), como os 
escrever era, assim, marca excepcional que particularizava o negro ou negra detentor de tais competências.

Apesar desse contexto sócio-histórico em tudo desfavorável e dos números limitados de alfabetizados, o trabalho de Oliveira mostra, porém, que a história da alfabetização no Brasil não é apenas uma história de brancos. Para isso, ele reuniu um corpus significativo de documentos e, entre eles, analisou 14 testemunhos escritos por escravizados ou como expressão de sua vontade (isto é, ditados a algum escrevente), encontrados na Bahia e preservados por uma irmandade negra denominada Sociedade Protetora dos Desvalidos, fundada em 1832. Nesses documentos destaca-se a presença do gênero carta que constitui 13 dos 14 textos. Tal dado permitiu que, entre outros aspectos, o pesquisador pudesse identificar que o uso do gênero epistolar esteve vinculado às constrições vividas por esses sujeitos.

Quase sempre marcadas pela brevidade e objetividade, as cartas analisadas tinham motivações pragmáticas tais como o cárcere; a distância geográfica, não raro motivada pelo tráfico interprovincial e outras formas de separações dos indivíduos que mantinham vínculos afetivos entre si; o encarceramento social, pedidos ou concessões de alforrias; além de suicídio, despedidas, revelações ou justificativas para a morte. Como gênero integrante do que foi denominado, sobretudo pela crítica francesa, como "escrita do eu", a carta reforça a noção de indivíduo e, por isso, adquire especial significância nesse contexto de anulação da subjetividade dos sujeitos escravizados. ${ }^{2}$ De acordo com Wander Melo Miranda, em diálogo com as proposições teóricas de Philippe Lejeune e de Michel Foucault:

a missiva, por definição destinada a alguém, dá lugar ela também ao exercício pessoal do missivista, pois a carta, pelo gesto mesmo da escrita, age sobre aquele que a envia, como age, pela leitura e pela releitura, sobre aquele que a recebe. Escrever é mostrar-se, fazer-se ver e fazer aparecer a própria face diante do outro: a carta é, ao mesmo tempo, um olhar que se lança ao destinatário e uma maneira de se dar ao seu olhar. A reciprocidade estabelecida pela correspondência implica uma 'introspecção', entendida como abertura que o emissor oferece para o outro para que ele o enxergue na intimidade (MIRANDA, 2009, p. 28).

As necessidades cotidianas que motivaram as cartas analisadas por Oliveira, assim, permitem que, para além das constrições sofridas, possa-se observar o modo de ser de cada um dos remetentes. Estes, cujas "faces" e "interioridade" desvelavam-se aos leitores atentos, enfrentavam o desafio de redigir as cartas, ou

regulamentos de 22 de abril de 1862 e de 27 de setembro de 1873 : $\mathrm{O} \S 3^{\circ}$. do art. 83, incluído no Cap. II do Título III sobre a instrução pública primária, incluiu os escravos entre os que não seriam admitidos à matrícula, nem poderiam frequentar as escolas primárias (Oliveira, 2005, p. 53).

2 Sobre isso, Wander Melo Miranda escreve: "Parece que é na relação epistolar que o exame de consciência se formula como uma narrativa escrita do $e u$, intencionada a fazer coincidir o olhar do outro e o olhar que se lança sobre si mesmo, no momento em que as ações cotidianas são medidas pelas regras de uma técnica de vida” (MIRANDA, 2009, p. 29). 
encontrar alguém que o fizesse (no contexto mencionado de poucos alfabetizados) e, depois, os diversos obstáculos para que as missivas chegassem aos seus destinatários. Muitos dos missivistas ficaram sem saber se os seus textos encontraram os correspondentes destinos. Esse foi o caso de Teodora Dias da Cunha, analisado por Oliveira e, de forma mais detida, por Maria Cristina Cortês Wissenbach (2012), no texto "Teodora dias da cunha: construindo um lugar para si no mundo da escrita e da escravidão". A trajetória da africana Teodora Cunha enquanto elemento constituinte da narrativa historiográfica ajuda-nos a refletir sobre a trama que envolve o romance Um defeito de cor, de Ana Maria Gonçalves (2006), e a carta escrita por Luiz Gama a pedido de Lúcio Mendonça em 188o, na medida em que o texto de Wissenbach coloca em cena cartas em que se enunciam as vozes de africanas em diáspora no Brasil na segunda metade do século XIX.

De modo análogo ao fato narrado no prefácio do livro de Gonçalves, a saber, o encontro pela autora-personagem dos manuscritos que configurariam o romance, conta Wissenbach que, ao analisar casualmente um processo, encontrou sete cartas escritas por solicitação de Teodora Cunha (as cartas foram ditadas por ela a distintos escribas). Notando que as correspondências não teriam sido enviadas, a historiadora assumiu o compromisso de torná-las públicas e de reconstituir a narrativa da vida de sua remetente:

Das sete cartas contidas no interior do processo, cinco delas foram escritas por Claro [a quem Teodora ditou as cartas] e duas outras por um escriba sobre o qual não existem indicações nos autos. Encontravam-se dirigidas a vários destinatários que, em sua quase maioria, nunca as receberam, uma vez que foram confiscadas pelas autoridades policiais. Dobradas na forma de envelope, contendo os respectivos endereçamentos, quatro seriam remetidas ao marido da africana, Luís da Cunha, cujo paradeiro ela desconhecia ou somente intuía; uma ao seu senhor, o cônego José da Terra Pinheiro, aliás, o único que supostamente a recebeu e leu; uma ao filho Inocêncio, cujo destino a escrava também ignorava, e a sétima seria enviada ao irmão do ex-senhor do marido, na tentativa de descobrir o paradeiro deste último (WISSENBACH, 2012, p. 229). ${ }^{3}$

Por meio das correspondências Teodora Cunha buscava "recompor sua família desmembrada pela venda, obter sua alforria e a de seu marido, e voltar à África" (WisSENBACH, 2012, p. 229-230). É isso o que podemos constatar ao lermos a carta dirigida a Luís da Cunha:

3 Claro Antônio dos Santos era um crioulo natural da província do Paraná, pedreiro, escravo de ganho e morador de São Gonçalo que foi indiciado como réu junto com Teodora e outro parceiro num inquérito policial que buscava averiguar um roubo na casa do escravizador da africana. A relação entre Claro e Teodora tem início por esta o ter procurado a fim de que ele, que sabia ler e escrever, redigisse suas cartas. 


\begin{abstract}
Meu marido Luis, São Paulo
Muito hei de estimar que Vance esteja com saúde/ eu estou aqui na cidade/ eu vos escrevo para Vance se lembrar daquela promeça que nos fizemos/ eu hei de procurar por voce/ mando muita lembrança para voce/ e ajunta um dinheiro la/ se puder vir falar comigo venha/ senão puder me manda a resposta e dinheiro vá juntando la mesmo/ se cazo me arranjar por aqui mando propia la. Dessa vossa mulher, Theodora, escrava do connio terra que foi vendida na vacaria. (PC 1492, p. 36) (WISSENBACH, 2012, p. 230).
\end{abstract}

Adentramos no âmbito da intimidade de Teodora Cunha, que se faz ver pela circunscrição expressa nas situações comunicativas das cartas. Por meio de uma escrita pessoal, a mulher busca retomar a promessa mútua que havia sido feita com o marido e que remete ao desejo da liberdade. A dúvida quanto ao estado de vida do companheiro ("se puder"/ "se não puder") divide terreno com a determinação de quem está disposta a enfrentar os mecanismos de anulação de sua subjetividade e, nesse contínuo, recuperar as relações pessoais que lhe são constitutivas ("eu hei de procurar por voce").

Na missiva endereçada a Inocêncio, acercamo-nos de outra faceta de Teodora Cunha. De seu texto reluz a afetividade da mãe que, apesar da distância e do desconhecimento em relação ao paradeiro do filho, deposita na escrita o desejo de saber da saúde deste e a expectativa de que, encontrando o seu destinatário, a carta possa comunicar, e nesse gesto efetivar, a benção materna devotada:

\footnotetext{
Ilmo Senhor inos senço

em São Paulo 20 de novembor de 1866

Meo filho eu hetima muito e a sua saude como para mim dezeio noto bem pa voes mi mandra scrita como vai de saude no mais eu bosto a minha bençao Deos te abeso para muito tempo ti dezeio como para mim dese noto bem para sou a tua maite a dora no mais a Deos

[Sobrescrito] Ilmo Senhor nocenso numa falzenda de pasto na Bipopara Jundiahi (PC 1492, p. 194) (WISSENBACH, 2012, p. 232).
}

O texto sintético, escrito a partir da incerteza, em sua unidade funciona como fragmento de uma narrativa maior, a saber, história da separação forçada de mãe e filho. É possível notar, ratificando as observações de Oliveira (2005), que o aspecto breve das cartas se vincula, como acrescenta Wissenbach (2012), a um evidente formalismo (protocolar à época), mesmo que se tratem de usos da língua portuguesa distantes das normas cultas e de maior prestígio social. Verifica-se, nesse sentido, marcas formais caracterizadoras do gênero carta em fusão com a presença notória da oralidade, explicitando o fato de os textos terem sido ditados, o que resulta numa linguagem que "corre solta e invade o ritmo das palavras escritas, encadeando pensamentos em uma grande rapidez" (WISSENBACH, 2012, p. 232). 
Essa mesma oralidade, conforme sublinha Oliveira (2005), era responsável por complementar a escrita, tanto no percurso da correspondência até os seus destinatários, processos que envolviam uma série de intermediários, quanto para que os pedidos e desejos expressos nas linhas escritas pudessem ser concretizados (não raro, como é possível ver na carta a Luís da Cunha, os textos pediam para que determinada pessoa fosse conversar com a remetente ou com outro sujeito relevante para a questão mote da carta ser resolvida). Isso mostra como a relação palavra escrita e palavra falada dava-se de modo complementar para o negro e negra viventes no período. Por meio das considerações de Teodora Cunha, torna-se possível tomar conhecimento acerca de algumas das percepções que os escravizados e forros tinham de sua própria condição, quais lhe eram as urgências e as concepções de mundo que determinavam seus atos.

A excepcionalidade e importância dessas correspondências (tanto as de Teodora Cunha quanto as outras analisadas por Oliveira) intensifica-se ainda devido ao fato de que na sociedade escravista brasileira, por uma série de constrições, são raros os relatos encontrados de negros e negras em que seja enunciado um "eu". Sendo assim, de modo a revelar um dado que desmente proposições que circularam nas malhas historiográficas do país até bem pouco tempo, a saber, a ideia de que a comunidade escravizada era alheia aos vínculos familiares e afetivos, os conteúdos das cartas de Teodora Cunha permitem Wissenbach (2012, p. 237) afirmar que:

em termos históricos amplos, as urgências de Teodora denotam a importância da família na vida dos escravos, notadamente como meio de concretizar as lutas e de substanciar a sensação de pertencimento. Como coloca de forma instigante Joseph Miller (2011, p. 22), "nada mais dilacerante aos escravos africanos do que o sentimento de estar só”.

De fato, ao lermos as cartas de Teodora Cunha, somos sensivelmente tocados pela experiência dessa mulher que parecia fazer da fé e da certeza de interlocução com os seus (ainda que indeterminada pelo silêncio da distância) uma estratégia para a conquista da liberdade e, além disso, o alento e alimento para suportar os mecanismos perversos do sistema de subalternização. Este, entre outras coisas, a afastava, como foi dito, não apenas dos recursos de uma oficialidade que lhe permitiriam delimitar as condições de uma vida livre, como o código escrito, mas também, e principalmente, da comunhão compartilhada com aqueles que se conectavam à sua terra natal e, assim, a presentificavam em suas múltiplas dimensões.

Essa riqueza de elementos presentes nos poucos registros em primeira pessoa produzidos pelos africanos e afrodescendentes no Brasil não pode ser encontrada na produção de relatos escritos por viajantes e investigadores brancos. Robert Wayne Slenes debruçou-se sobre esse material e, segundo seu estudo, nele são escassas e sintéticas "suspeitas e pouco confiáveis" as descrições concernentes à 
vida íntima dos escravizados (SLENES, 2011, p. 135-136). Esse aspecto é um dos temas centrais dos estudos de Slenes, focado na região sudeste do país. Ao tentar recuperar o projeto dos escravizados para a "vida familiar" e as "esperanças" e "recordações" que os orientavam em oposição aos quadros patológicos e degradantes com que essas populações foram pintadas pelos observadores do século XIX (e isso, conforme escreve Slenes, diz mais sobre os "desvios do olhar do branco" do que sobre o "lar negro" propriamente dito), ele afirma que:

os africanos trazidos ao Sudoeste do Brasil, apesar da separação radical de suas sociedades de origem, teriam lutado com uma determinação ferrenha para organizar suas vidas, na medida do possível, de acordo com a gramática (profunda) da família-linhagem. Encontrando, ou forjando, condições mínimas para manter grupos estáveis no tempo, sua tendência teria sido empenhar-se na formação de novas famílias conjugais, famílias extensas e grupos de parentesco ancorados no tempo (SLENES, 2011, p. 147).

Nesse sentido, ainda que saibamos que a legitimação da condição humana da comunidade africana, em diáspora forçada no Brasil, não se limita ao seu pertencimento e/ou desejo de uma estrutura familiar, faz-se significativo tal estudo - que tem seu subsídio na análise das marcas pessoais que os africanos imprimiam à sociabilidade da época e na arquitetura de suas moradias, por exemplo. A proposição de Slenes se destaca sobretudo como contraposição, em chave revisionista, aos discursos de obras do século XIX, como a de Louis Couty. Segundo Slenes, Couty deixou o maior relato que se tem sobre famílias escravas no sudeste do Brasil, no qual, porém, as mães negras são descritas como desalmadas (não sabem o número de filhos que tiveram e nem por onde eles andam) e as esposas negras como assassinas (SLENES, 2011, p. 135).

As pesquisas de Slenes e Wissenbach se complementam e subsidiam que esta última possa ler a enunciação feita por Teodora Cunha sobre a necessidade de se obter a carta de alforria e assim poder restituir sua família e voltar à África, como uma forma de a escravizada, ainda que analfabeta, "construir um lugar para si no mundo da escrita e da escravidão" (WISSENBACH, 2012). Verifica-se, dessa maneira, a intrínseca relação entre o domínio do código escrito e a inscrita de si, enquanto corpo e subjetividade, na rede discursiva que legitima a existência de uma individualidade. As cartas de Teodora Cunha condensam em amplitude semântica o enredo singular de sua família, mas, ao serem lidas desde a historiografia, séculos depois, também remetem, como reitera Wissenbach, a dilemas cotidianos vividos por um conjunto maior de escravizados, dando a ver percepções que não lhe pertenciam exclusivamente. Nesse sentido, é possível depreender que o gênero carta, enquanto "escrita do eu" no contexto escravocrata, perfaz um texto em primeira pessoa do singular $(e u)$ que, contudo, permite que contemporaneamente entrevejamos uma enunciação coletiva referente à primeira pessoa do plural (nós). 
Logo, a intervenção da História na leitura e interpretação das cartas opera um deslocamento da delimitação desse gênero textual ao atribuir o sentido coletivo e a dimensão pública a uma escrita íntima que pressupõe uma troca particular entre um remetente e um destinatário. Desse modo, o trabalho de Wissenbach permite não só que reconheçamos a relevância do gênero carta para a população negra no contexto da escravidão brasileira, mas igualmente sua centralidade na investigação dos historiadores comprometidos a produzir conhecimento a partir da perspectiva dos que foram subalternizados.

Numa justaposição provocativa, Um defeito de cor poderia ser lido como um (im)possível desenvolvimento de cartas como a de Teodora Cunha. Sem deixar de afirmar-se como romance, a obra se conforma fazendo uso da complexa interpenetração entre os gêneros que compõe as "escritas do eu" e declara-se como uma carta, transbordando para o campo do texto memorialístico. O enredo efetua-se assim como epístola na qual a remetente, uma africana liberta, afirma desejo semelhante ao expresso na enunciação de Teodora Cunha: restituir parte de sua família, no caso, o filho perdido. A esperança de que o filho seja encontrado e o medo de que sua vida não alcance tal momento motiva a mãe-narradora a elaborar o relato de sua trajetória, o qual garantiria condições para esse encontro mesmo após a sua morte.

O já mencionado dado fundamental à construção narrativa, a saber, a ideia de que os supostos manuscritos dessa correspondência teriam sido encontrados por Ana Maria Gonçalves, como instância ficcionalizada do prólogo, numa igreja na ilha de Itaparica, criam a apontada analogia entre o modo como se representam as atuações de Wissenbach e de Gonçalves. Assim como a historiadora, a autorapersonagem declara que diante da incerteza de que a carta de Kehinde tenha alcançado o seu destinatário, incumbiu-se, mesmo tantas décadas depois, de traduzila, organizá-la e reconstituir a história nela registrada, publicando-a em forma de romance. Reitera-se a carta como significativo gênero textual no contexto escravista e o romance como texto configurado a partir da suplementariedade entre literatura e história.

Chegaram as cartas de Teodora Cunha e de Kehinde a que destinatários? Assim como a análise da historiadora, o construto literário realiza uma reorientação da escrita de outrem. Isto é, a trama de Um defeito de cor não permite que confirmemos o recebimento da carta por parte do sujeito expresso nela como destinatário (a epístola de Kehinde sequer apresenta formalmente uma despedida caracterizadora do gênero). Luana Antunes Costa (2014) ao elaborar a análise do texto ferusalém, de Mia Couto, que ela define como diário-epistolar, dialoga com as proposições de Nádia Gotlib e sublinha que o gênero carta coloca em evidência aquele que escreve, o remetente, mas para isso se funda na ausência do interlocutor, o destinatário, e aponta, pois, ao seu paradeiro. Sendo assim, segundo ela: 
O espaço da ausência do outro é suplantado pela escrita da carta, inscrição da voz daquele que escreve direcionada ao interlocutor deslocado. A ausência configura-se como uma força desencadeadora da circularidade vocal: o outro lê e a partir de sua leitura escreve, forja em seu texto suas próprias impressões, grafia, sob o texto do outro, o seu suplemento (COSTA, 2014, p. 181-182).

Depreende-se, então, que se o corpo da missivista performatiza-se (a "face" e a "interioridade" vem à luz) na carta, num gesto implícito que preenche a presente lacuna do destinatário, este também ("suas impressões", "grafias") se corporifica. Gonçalves (2006) e Wissenbach (2012) imprimem em seus textos e convocam novos interlocutores, os quais, se vistos em aproximação com a ideia de destinatário recuperada aqui na citação de Costa, passam a constituir a circularidade vocal disparada pelas vozes que se configuram nas cartas e, por meio da leitura, participam da escritura delas.

Em conexão com esse redirecionamento do destinatário, ressignifica-se também os efeitos de leitura que as correspondências postas em cena produzem. Se em muitos aspectos a carta analisada por Wissenbach e aquela editada pela autora-personagem Ana Maria Gonçalves apresentam pontos de contato e coincidências, principalmente no que se refere às constrições sócio-históricas que justificam suas enunciações, em outros, a começar pela extensão, vemos o romance suplementar a narrativa histórica e pôr em ação uma complexa estrutura enunciativa, a qual, por sua vez, remete a recursos composicionais de uma outra famosa carta produzida por ex-escravizado e se blinda, como veremos a seguir, a tentativas monolíticas de interpretação.

\section{Duas cartas enredadas numa trama literária}

A polissemia constituinte da narrativa que se investe como literária permite que o foco narrativo de Um defeito de cor seja lido de diversas maneiras; entre elas, seria pertinente compreender a narradora - ou a remetente da carta - como Kehinde, uma daomeana que, tendo conseguido sua alforria e voltado à África, adota por razões estratégicas o nome Luísa Andrade Silva e torna-se, primeiro, uma rica comerciante e, depois, uma poderosa empresária do ramo da construção civil de Uidá e Lagos. ${ }^{4}$ Seria, assim, a voz de Kehinde quem apresenta seu núcleo familiar e em seguida situa o início da história num episódio traumático de sua infância: o assassinato da mãe e do irmão e a necessidade de abandonar, com a avó e a irmã, o lugar onde vivia:

Eu nasci em Savalu, reino de Daomé, África, no ano de um mil oitocentos e dez. Portanto, tinha quase sete anos quando esta história começou. O que

4 As mudanças de nome da narradora apontam para a construção elaborada e prenhe de contradições de sua identidade. 
aconteceu antes disso não tem importância, pois a vida corria paralela ao destino. O meu nome é Kehinde porque sou uma ibêji e nasci por último. Minha irmã nasceu primeiro e por isso se chamava Taiwo. Antes tinha nascido o meu irmão Kokumo, e o nome dele significava "não morrerás mais, os deuses te segurarão”. O Kokumo era um abiku, como a minha mãe. O nome dela, Dúróoríike, era o mesmo que "fica, tu serás mimada". A minha avó Dúrójaiyé tinha esse nome porque também era uma $a b i k u$, e o nome dela pedia "fica para gozar a vida, nós imploramos" [...] E era por isso que [a avó] estava nos tirando de lá, pois tinha acontecido algo do qual nunca mais conseguiríamos esquecer. Até aquela hora, desde a hora do destino, nenhuma de nós três tinha falado nada, e foi assim, em silêncio, que pegamos a estrada sem que eu e a Taiwo soubéssemos para onde. Talvez a minha avó já soubesse, ou talvez tenha decidido quando estávamos a caminho (GoNÇALVES, 2006, p. 19, 26).

Ao chegarmos ao final do livro, entretanto, declara-se que o relato é fruto de uma enunciação oral e que devemos o seu registro a Geninha, acompanhante e ouvinte de Kehinde, que escreve, ao longo de uma viagem marítima em direção ao Brasil, a carta ditada pela senhora já cega:

Tive a ideia de fazer esse relato três dias antes da partida, quando pedi ajuda da Geninha e mandei comprar papel. O que eu imaginava ser uma carta de dez, doze páginas, porque sabia que não viveria até te encontrar, já se transformou em tantas que nem temos coragem ou tempo para contar, colocadas em uma pilha enorme aqui ao lado de minha cama. Sorte que percebemos isso ainda antes de embarcar, quando então mandei comprar mais papel, muito mais, a Geninha acaba de me avisar que nem foi tão exagerado quanto imaginávamos a princípio. Passando os dias dentro desta cabine, ditando o que ela vai escrevendo, somente agora, no final da viagem, é que começo a pensar no que significa voltar ao Brasil, embora eu nada vá ver dos lugares dos quais ainda me lembro. A Geninha verá por mim, e também fica encarregada de fazer com que tudo isto chegue às suas mãos (GoNÇALVEs, 2006, p. 912, grifo nosso).

Cega, sem poder ler e escrever (ainda que detenha tais capacidades, um dos fatos determinantes para sua emergência conforme a narrativa em diversas passagens sublinha), Kehinde confia a redação da carta com o registro de sua vida a Geninha, que ao efetivar a transcrição do texto oral para o escrito insere uma nova instância no campo da produção do relato. Ainda assim, a dicção da idosa como uma contadora de histórias tinge a narrativa e se torna mais audível conforme esta avança para o seu desfecho, fazendo-se recorrentes as lacunas da memória sobre os episódios vividos e as considerações acerca da situação enunciativa, o que, conforme o trecho supracitado mostra, inclui comentários sobre a extensão da carta e sobre a proximidade com a morte.

À potência dessa delimitação do foco narrativo funde-se a concepção da fala da narradora enquanto voz de uma mulher que entrou para a história (literária?) 
como mãe, a partir, não coincidentemente, de outra carta, a saber, aquela escrita por Luiz Gonzaga Pinto da Gama ou simplesmente Luiz Gama. ${ }^{5}$ Nessa famosa carta enviada em 1880 ao amigo e jornalista Lúcio de Mendonça, atendendo ao pedido de que contasse sua história, Gama nomeia uma africana, Luíza Mahin, como mãe e a apresenta ao leitor:

Sou filho natural de uma negra, africana livre, da Costa Mina (Nagô de nação), de nome Luiza Mahin, pagã, que sempre recusou o batismo e a doutrina cristã. Minha mãe era baixa de estatura, magra, bonita, a cor era de um preto retinto e sem lustro, tinha os dentes alvíssimos como a neve, era muito altiva, geniosa, insofrida e vingativa. Dava-se ao comércio - era quitandeira, muito laboriosa, e mais de uma vez, na Bahia, foi presa como suspeita de envolver-se em planos de insurreições de escravos, que não tiveram efeito. Era dotada de atividade. Em 1837, depois da Revolução do dr. Sabino, na Bahia, veio ela ao Rio de Janeiro, e nunca mais voltou. Procurei-a em 1847, em 1856 e em 1861, na Corte, sem que a pudesse encontrar. Em 1862, soube, por uns pretos minas, que conheciam-na e que deram-me sinais certos que ela, acompanhada com malungos desordeiros, em uma 'casa de dar fortuna' em 1838, fora posta em prisão; e que tanto ela como os seus companheiros desapareceram. Era opinião dos meus informantes que esses 'amotinados' fossem mandados por fora pelo governo, que, nesse tempo, tratava rigorosamente os africanos livres, tidos como provocadores. Nada mais pude alcançar a respeito dela. Nesse ano, 1861, voltando a São Paulo, e estando em comissão do governo, na vila de Caçapava, dediquei-lhe os versos que nesta carta envio-te (GAMA, 188o, grifo nosso).

Escancarando a ainda insuficiência do que alcançamos sobre as experiências negras ao longo do século XIX no Brasil, a descrita conjuntura de obstrução do acesso à letra aos africanos e seus descendentes também engendrou a figura de Gama que, sendo ex-escravizado, tornou-se erudito abolicionista, escritor e rábula (de modo a produzir mais uma conexão elíptica no encontro das narrativas, Wissenbach (2012, p. 236) indica a alta probabilidade de que Luiz Gama tenha conhecido Teodora Dias da Cunha, na medida em que ele foi um dos peritos a realizar o exame de corpo delito presente do processo criminal do qual participava a africana e ao qual foram anexadas as cartas dela). Nessa carta, podemos ver a primeira inscrição - que será seguida por inúmeras outras - do nome Luíza Mahin numa rede discursiva que passará a conectar, direta ou indiretamente e sempre com variações, os signos Luiz Gama, escravidão, abolicionismo, Luiza Mahin, Revolta dos malês e mulheres negras.

5 Como uma das possíveis descrições do autor, podemos ler o seguinte trecho escrito por Lígia Fonseca Ferreira: "Examinados em seu conjunto, os escritos de Luiz Gama nos mostram que foi um grande comunicador e de ampla tessitura: do escravo ao imperador, dirigia-se a todas as camadas da população [...]. Luiz Gama expressou-se por variados gêneros e todos os meios (mídias, diríamos hoje) a seu alcance. A palavra era seu ethos, seu trabalho, mas também sua diversão. Do silêncio e ignorância impostos ao escravo, Luiz Gama, que se constrói como sujeito eminentemente político, conquistou autonomia e o direito de ter voz - ou seja, de comentar, opinar, de protestar, de denunciar, enfim de se expressar publicamente com total liberdade - desfrutando do que entendia ser 'cidadania', razão pela qual dispensou porta-vozes' (FerReIRA, 2011, p. 20). 
Foram os atributos na carta indicados, e grifados no excerto citado, que serviram de núcleo da caracterização da narradora de Um defeito de cor. Conforme explicita, em entrevista, a autora Ana Maria Gonçalves, em seu romance estaríamos diante de uma das atualizações de Luíza Mahin:

O que eu tomei como história de Luiza Mahin, ao construir o livro, o que coloco como biografia dela, foi através do que o Luiz Gama deixou escrito. Quando ele diz: minha mãe era uma negra altiva.... ele deixou a descrição física dessa suposta mãe e eu me apropriei da história contada, ou inventada por um poeta. Achei interessante essa criação da figura da mãe, feita por um poeta, que eu transformei em prosa. Minha intenção era ficcionalizar o que estava ficcionalizado à sombra disso (GonçALves, A.M., 2010, s/p, grifo nosso). ${ }^{6}$

É estabelecida uma intertextualidade direta entre o romance e a carta de Gama de modo que declarar, no nível da intenção, o desejo de "ficcionalizar o que estava ficcionalizado" constitui a narradora do livro como uma figura cuja autoria é, em algum sentido, compartilhada com o reverenciado autor do século XIX. Sendo assim, a obra de Gonçalves também pode ser lida como o registro particular da vida de Luíza Mahin, mãe de Luiz Gama. São explícitas as referências que o romance estabelece entre a narradora e essa figura, a começar pelo seu prólogo. Revisitandoo, notamos que a identidade entre a narradora e Luíza Mahin surge como uma inferência que o leitor é induzido a fazer:

\begin{abstract}
Mesmo porque esta pode não ser uma simples história, pode não ser a história de uma anônima, mas sim de uma escrava muito especial, alguém de cuja existência não se tem confirmação, pelo menos até o presente em que escrevo esta introdução. Especula-se que ela pode ser apenas uma lenda, inventada pela necessidade que os escravos tinham de acreditar em heróis, ou, no caso, em heroínas, que apareciam para salvá-los da condição desumana em que viviam. Ou então uma lenda inventada por um filho [...] que nasceu livre, foi vendido ilegalmente como escravo, e mais tarde se tornou um dos principais poetas românticos brasileiros, um dos primeiros maçons e um dos mais notáveis defensores dos escravos e da abolição da escravatura (GonçALVEs, 2006, p. 16-17, grifo nosso).
\end{abstract}

Dessa maneira, Um defeito de cor perfaz Kehinde como uma representação de Luíza Mahin e, nesse contínuo, o seu filho desaparecido, destinatário enunciado da carta, como Luiz Gama. Os elementos que caracterizam a história de Gama

\footnotetext{
6 A presença da mãe na obra de Gama também aparece no poema “Minha mãe”, publicado em 1861 e mencionado na carta a Lúcio de Mendonça. Por haver diferença entre a forma de caracterização da mãe no poema e na carta e ser este segundo o texto cujo gênero é o mote do livro de Gonçalves, optamos por restringir nossa análise a essa referência, a qual, como será demonstrado, tem diversos elementos recuperados pelo romance.
} 
(descritos por ele mesmo na carta a Mendonça) são incorporados ao enredo do romance e correlacionados à narradora, a qual, além das características físicas, também detém o sublinhado traço da rebeldia e o nome de Luísa Gama, sendo "Gama" sobrenome de seu primeiro escravizador, José Carlos de Almeida Carvalho Gama, adquirido na experiência de chegada ao Brasil. Nesse contínuo, tem-se no enredo do romance a narração de que, assim como Luiz Gama afirma em sua carta, o filho de Luísa Gama, Omotunde ou Luiz, nascido livre, teria sido vendido como escravo pelo próprio pai, um português. Sem abandonar o campo dessas congruências constatáveis, indica-se o fato de a narradora ter diabetes, doença que a deixa cega e que, sendo hereditária, levou à morte, como é sabido, Luiz Gama.

Não sendo poucos os diálogos entre mãe e filho ao longo do romance em que se estabelece essa relação de similaridade, a explicitação da referência aparece diretamente no desfecho da obra, quando Kehinde - a quem passarei nesse artigo a me referir como Luísa ${ }^{7}$ - encontra cartas que davam notícia da vida do filho, as quais confirmam a coincidência entre os caminhos de Luiz e Luiz Gama e revelam que a busca empreendida anos antes pela mãe esteve no encalço correto:

Na segunda carta, ele dava muitos detalhes de você, contando tudo sobre a sua vida, que você era amanuense e que também advogava em favor dos escravos, conseguindo libertar muitos deles. Que você estava casado, tinha filhos e era maçom, que escrevia poesias e era muito respeitado por publicar artigos belíssimos e cheios de inteligência nos jornais mais importantes da cidade, e dava inclusive a sua morada (GonçALVES, 2006, p. 946, grifo nosso).

Sem deixar de grifar que é também por meio de cartas que Luísa recebe (e descobre com atraso significativo) as notícias, parece potente observar que esse gênero discursivo adquire nova significância na análise em curso na medida em que atrelado à ideia de ficção (e autoficção) conecta ambas as narrativas, a de Gama e a de Gonçalves.

De acordo com Lígia Fonseca Ferreira (2008, p.303), para que seja apreendido o alcance da carta de Gama é necessário reexaminá-la considerando seu contexto de produção (histórico e individual) e as motivações de sua recepção de modo a flagrar os elementos objetivos, subjetivos e intersubjetivos amalgamados na produção do relato. Ela se propõe a realizar tal tarefa e a partir da análise afirma (evocando as considerações desenvolvidas no primeiro segmento desse artigo) que, se por um lado a carta reflete uma relação privilegiada entre seus interlocutores -

7 É curioso que a autora opte pela grafia com “s” em diferença a Luiza, com “z”, que Gama inscreve em sua carta. Isso parece constituir mais uma estratégia de afirmar uma relação de similaridade não idêntica entre Luísa Gama e Luíza Mahin. Em determinados momentos, a narradora joga com a variação dos nomes, mostrando um gesto autoconsciente nessa mobilização: "quase toda Bahia sabia da existência em Uidá de uma Kehinde, ou de uma dona Luísa, ou sinhá Luísa, que tinha enriquecido depois de montar uma firma que construía casas” (GonÇALvEs, 2006, p. 947). 
Gama e Mendonça -, por outro, ela atingiu uma significância que extrapolou essa condição de escrito íntimo e atravessou o tempo de forma a constituir toda uma coletividade como sua destinatária (FERREIRA, 2008, p. 302-303).

"Gama revela ocultando", conforme propõe Ferreira (2008). Marcado pela brevidade, própria do gênero carta, o texto do escritor é composto por informações que, não sendo possíveis de serem autenticadas, enuncia, de modo indeterminado, episódios e personagens que teriam constituído a sua trajetória. Contudo, é sobre a figura materna e sobre os meios pelos quais ele teria conseguido comprovar sua liberdade (rasurada pelo pai que o vende como escravo), dois temas de extrema relevância, que se verifica, de acordo com ela, especial "economia narrativa" da carta, o que a leva a escrever:

Onze palavras escondiam uma longa história que sem dúvida envolvia o pai, única pessoa a poder comprovar juridicamente que Luiz Gama havia nascido livre. A narrativa instaura, assim, uma ação quase mágica e envolve em certo mistério o passado de Luiz Gama que, de início, promete toda a verdade a seu destinatário (FERREIRA, 2008, p. 307, grifo nosso).

Conforme Ferreira demonstra, ainda que seja possível reconhecer indicadores textuais que ratificam a elaboração do texto enquanto carta (o que, dentre outros fatores vinculados às práticas sociais que circunscrevem os gêneros textuais, o distancia da autobiografia), em sua discursividade também se nota a consciência de que o discurso elaborado teria como destinatário um conjunto de leitores. A presença implícita desses leitores é responsável pela organização e seleção dos fatos narrados a partir da preocupação de Gama com sua autoimagem. Sendo assim, memória e construção narrativa aliam-se e produzem um relato que, por vezes, instaura a dúvida sobre a identidade do remetente. ${ }^{8}$

São tais procedimentos que possivelmente fundamentam a proposição de Gonçalves quando no prólogo do romance a remissão à presença de Mahin na carta de Gama é concebida como "uma lenda inventada por um filho" (2006, p. 17). A carta de Gama apenas muitos anos depois de sua escrita foi publicada integralmente, em 1930, e, na condição de um dos poucos "registros do eu"9 produzidos por um ex-escravizado no Brasil do século XIX, deu origem a uma vasta fortuna crítica e a inúmeras incorporações intertextuais (inclusive, como é o caso em análise, pela literatura). Não surpreende, pois, que essa missiva tenha lugar central

\footnotetext{
8 Gama afirma, por exemplo, que teria sido batizado em Itaparica, mas, segundo o resultado das buscas de pesquisadores, não há nenhuma certidão de batismo nessa ilha que ateste tal episódio e com ele a identidade do autor. Tendo ciência disso, Ferreira afirma: "Gama colaborou voluntaria ou involuntariamente para a construção de sua própria lenda que, em nome da História, muitos se encarregariam de manipular" (2008, p. 321).

9 Também Ferreira recupera e privilegia a ideia de "escrita do eu", nesse caso mediada por Georges Gusdorf, a qual, segundo ela, pressupõe uma escrita para outrem, por exemplo, uma carta ou autobiografia, e distancia-se de uma "escrita de si", da qual o diário poderia ser um exemplo (GUSDORF, 1991 apud FERREIRA, 2008, p. 320).
} 
numa obra que, séculos depois, propõe-se a reelaborar a perspectiva negra desse período. A singularidade de Gonçalves reside, então, em atribuir à mãe de Gama a voz da primeira pessoa do romance, projetando um espelho no qual mãe e filho constituem e são constituídos por meio de uma troca de correspondência mútua e interceptada. A encenação textual desse (des)encontro entre mãe e filho, agora visto desde a perspectiva materna, ganha relevância histórica e recupera de modo profundo um estatuto sobre a comunidade negra no Brasil. Vemos, assim, perdurar na contemporaneidade a condição constituída no regime escravista, segundo a qual, tal comunidade é subalternizada, econômica e socioculturalmente, e destituída de suportes efetivos para a consumação de seus direitos mais básicos, inclusive no que diz respeito às possibilidades de construção familiar.

Gonçalves manteve-se atenta ao caráter fabuloso da carta Gama e ao seu "intenso sentimento filial" que, de acordo com Sílvio Roberto dos Santos Oliveira (2004, p. 36), um dos intérpretes da obra do autor, é contundentemente expresso na epístola e torna-se apreensível pela reconstituição seletiva do percurso de vida que Gama realiza. Se vista como uma narrativa, tal como propõe Santos Oliveira (2004, p. 54), a carta tem como "molas do conflito móvel" o desaparecimento da mãe e o afastamento do pai, que, por sua vez, seriam responsáveis pelas perdas da origem e da liberdade que marcaram a vida de Gama. Desse modo, a interpretação de Santos Oliveira aponta como Gama recupera apenas parte de sua origem: fornece dados sobre a mãe, mas cala no que se refere ao pai - sinalizando, assim, segundo o pesquisador, o desejo de lembrança daquela e de esquecimento deste.

A figura da mãe é apresentada como um símbolo valorizado no relato em correspondência com a qual Gama se constrói no texto. Em sua elaboração discursiva, porém, essa valorização se dá também pela já sinalizada "economia narrativa", na medida em que apenas três qualidades da mãe foram indicadas - inteligência, altivez e coragem -, além do fato de que ela teria se envolvido em atividades revolucionárias e fugido ao Rio de Janeiro antes de Gama completar oito anos. Isso leva Santos Oliveira a constatar que Luíza Mahin é descrita mais a partir de lacunas do que de informações: "ela teria fugido realmente para o Rio de Janeiro? Teria sido morta? Teria sido expulsa do Rio de Janeiro para outro lugar? Teria sido forçada a retornar à África?" (OliveirA, 2004, p. 36). A conclusão a que chega o intérprete é que a africana seria, assim, uma presença-ausência na vida de Gama (que, conforme declara na correspondência, procurou-a por 15 anos, de 1847 a 1862):

Luíza Mahin está presente e está ausente na carta. O significado dessa ausência/presença é que Luíza foi lembrada pela falta: esteve presente porque existiu a busca; esteve ausente por ser o motivo da busca. Gama sonhou com a mãe a chamá-lo: gritou espavorido, assustou os colegas. A mãe, sumida enquanto personagem da história, tornou-se a sombra de Gama no percurso heroico. No relato, a mãe é sempre uma ausência, mas nunca um esquecimento (Oliveira, 2004, p. 61). 
A relação instigante entre Gama e Mahin que a leitura de Santos Oliveira constata pode ser refletida à construída em Um defeito de cor. Para a narradora Luísa, a ausência do filho, Luiz, é também uma busca que mobiliza a narrativa de modo que o personagem ausente é presentificado ao tornar-se destinatário da carta. A falta de Luíza, no relato de Gama, assim como a de Gama, no relato de Luísa, é preenchida de significados e se, inicialmente, instaura-se entre ambos uma diferença que confere ao primeiro o status de documento em detrimento do caráter ficcional do segundo, logo, em acordo com o que antecipamos anteriormente, a análise crítica complica tal dicotomia:

A maior parte das pistas fornecidas parecem comprováveis, mas nunca foram comprovadas. Não há como descartá-las. Porém, se as informações não foram acompanhadas de provas, podem ter funcionado mesmo como despistes. Não é possível afirmar que Luíza Mahin existiu e que o pai fosse "branco". É possível até duvidar da confissão de Gama. Porém, o mais recomendável é tentar perceber como Luíza Mahin passou a existir depois do relato de Gama pelo excesso e como o pai passou a existir depois do relato pela falta. Gama driblou o aspecto documental: simplesmente desobrigou a outros de perscrutarem seu passado (Oliveira, 2004, p. 48, grifo nosso).

As estratégias que permitem o "drible [d]o aspecto documental" operado por Gama em sua narrativa viabilizam a interpretação da dimensão ficcional da carta. Essas lacunas e silêncios constitutivos do texto, segundo Santos Oliveira, fomentaram um "excesso de palavras", o qual tem em Um defeito de cor uma das realizações que afirmam o "mito Mahin".

Explicando melhor a reverberação desse "excesso" e o processo pelo qual a figura de Mahin foi alçada à condição de mito e, posteriormente, passou a atuar como símbolo que reconfigura a identidade feminina negra, encontramos a dissertação de Dulcilei da Conceição Lima (2011), produzida na área de Educação, Arte e História da Cultura e intitulada Desvendando Luíza Mahin: um mito libertário no cerne do feminismo negro. Para dar cabo da investigação, Lima inicialmente analisa as três primeiras publicações em que se registra o nome de Mahin, a saber, a carta de Gama, de 1880, o romance de Pedro Calmon, "Malês: a insurreição das senzalas, de 1933, e o livro O negro na civilização brasileira, publicado em 1956 por Arthur Ramos.

Se no texto de Gama é descrita como mãe, africana altiva e insurgente, Mahin, na obra literária marcada pelo racismo científico de Calmon, torna-se uma princesa ardilosa e lasciva que mantém ódio pelos brancos e atua na Revolta dos Malês a fim de exterminá-los, mas acaba por trair seus companheiros rebeldes. Já no texto de Ramos, nota-se, conforme a pesquisadora avança na análise, a recuperação do enaltecimento da africanidade de Mahin para, desde o campo científico em que está situada a obra do intelectual, conferir-se um tipo de "atestado" à existência da africana e à sua ligação com a Revolta dos Malês: 
Ramos afirma que Luiza Mahin foi liderança na revolta do malês e que é um 'símbolo do valor da mulher negra', atribuindo a ela, portanto, conotação positiva ao contrário de Calmon. A materialidade histórica de Luíza advém dessa menção num documento acadêmico de um antropólogo conhecido (LiMA, 2011, p. 64).

A partir dessa genealogia discursiva, que é constantemente reiterada e ressignificada, conforme o trabalho minucioso de Lima expõe, os movimentos de mulheres negras, em resposta ao cenário de violência exercido pelos estereótipos de representação das mulheres negras, legitimaram a figura de Mahin e, mais do que isso, através de uma série de ações (textos literários, saraus, referências nominais, músicas etc.) atuaram no sentido de fazer esse nome vigorar positivamente no imaginário coletivo. Já investido de autonomia, o signo Mahin ganhou consistência e criou condições para que fosse alçado ao status de mito, tal qual analisado por Lima, de modo que: "As mulheres negras transformaram Luíza Mahin e foram transformadas por ela, pois a partir de referenciais positivos e tanto outros puderam repensar a si próprias; articular a mobilização e empreender suas lutas" (LIMA, 2011, p. 126).

Esse significativo processo de representação racial afirmativa a partir da figura de Luíza Mahin coexiste com a indeterminação acerca da experiência social dessa mulher, na medida em que, desde a História, não houve alteração no estamento que nega a existência dela enquanto "personagem histórica". Desse modo, em seus significativos estudos sobre a Revolta dos Malês, João José Reis é contundente ao afirmar:

Nenhuma Luíza, aliás, foi incluída em quaisquer listas de presos por envolvimento no levante. A única mulher com esse nome que encontrei em 1835 foi uma liberta, presa provavelmente em novembro para ser deportada por crime não especificado, mas de forma alguma por insurreição. [...] O personagem Luíza Mahin, então, resulta de um misto de realidade possível, ficção abusiva e mito libertário. A rigor, o que dela se conhece tem pouca fundamentação histórica. O que mais se aproxima dela é o pouco que sobre ela escreveu o filho Luiz Gama. Do que este revelou, o envolvimento da mãe em 1835 é até possível, embora os documentos sobre a revolta não o confirmem e indiquem como altamente improvável seu papel de liderança (REIS, 2003, p. 301-303, grifo nosso).

A partir do reconhecimento dessa tensão entre a história e a legitimação social, e na área dos Estudos de Linguagem, Aline Najara da Silva Gonçalves produziu, em 2010, a dissertação Luiza Mahin entre a ficção e a história. Desse modo, à luz da bibliografia recente dos estudos historiográficos e do romance de Ana Maria Gonçalves, a pesquisadora realiza um detido levantamento em busca dos lastros de Mahin e chega à conclusão de que, diante da falta de "fontes históricas" que verifiquem a existência de Mahin, o romance de Gonçalves constitui-se como um tipo de "narrativa reparatória", isto é, uma narrativa que deliberadamente dá existência para uma imagem importante na "memória coletiva do povo negro brasileiro": 
Trata-se de um mito cristalizado, mas, ainda assim, móvel, na medida em que transita em campos variados a ponto de ser apropriada de formas distintas. É justamente nesta dinâmica que está sua singularidade. Ao adentrar o terreno da subjetividade, preenchendo uma carência historiográfica em resposta a um anseio há tempos reclamado pela memória afrobrasileira (GoNÇALvES, A.N.S., 2010, p. 91).

Para Silva Gonçalves, o romance se projetaria como documento que valida a existência, a despeito da recusa da historiografia, de Mahin. Um defeito de cor, então, viria a se somar ao conjunto de expressões que dão forma ao "anseio" mencionado, tais como ações, sobretudo por parte da militância negra, que fazem com que o nome de Mahin seja rememorado em nomes de praças, escolas, monumentos, obras literárias etc. ${ }^{10}$

Como tem sido demonstrado ao longo deste artigo, as comunidades negras no Brasil precisam lidar com o fato de que sua relação com a palavra escrita foi sistematicamente obstruída e como gesto correlato a essa tentativa de interdição os poucos documentos escritos que registrem as experiências individuais e percursos sociais dos indivíduos constituintes desses grupos ao longo dos séculos XVIII e XIX foram rasurados, quando não destruídos. Se vistos a partir desse contexto, os episódios que circunscrevem o nome de Luíza Mahin visam atribuir autenticidade à trajetória dessa mulher e criam um sistema de reconhecimento e reprodução social à revelia do discurso historiográfico e, nesse sentido, em tensão com o enunciado que se vincula ao campo concebido como produtor científico de conhecimento.

Um defeito de cor, como componente de um outro sistema de produção de conhecimento e em sua dimensão ficcional de carta, pode ser lido como uma encarnação da voz de Mahin. O livro coloca em centralidade o corpo dessa mulher, o qual sobrevive, ainda que visto desde as posições hegemônicas como defeituoso, e encontra o leitor por meio da voz materna transfigurada como dicção do relato. Resgatando o que foi dito sobre a presença dos interlocutores nesse gênero textual, através do cotejo da carta de Luiz Gama com a carta de Luísa Gama, constituinte do romance de Ana Maria Gonçalves, é possível afirmar que o filho concebe sua mãe discursivamente e esta, por sua vez, concebe o filho igualmente em sua narrativa. A busca fracassada que ambos descrevem em seus relatos, por um lado, coloca em pungente evidência a impossibilidade do encontro mútuo e nisso, de modo simbólico, sinaliza algo sobre a dificuldade de assunção da ascendência africana no Brasil e diametralmente do exercício da maternidade negra (vereda que desenvolvo em outros trabalhos). Por outro lado, esse mesmo (des)encontro pode ser lido como a constituição de uma equação na qual Gama, enquanto perso-

${ }^{10}$ Lima, que também analisa Um defeito de cor, escreve: "As memórias de Luiza Mahin [no romance de Gonçalves] preenchem, assim, as lacunas na carta de Luiz Gama. Tais artifícios utilizados pela autora contribuem para o fortalecimento, poderíamos mesmo dizer renovação, do mito sobre a africana insurreta" (2011, p. 87). 
nagem histórico, elabora a autoficção de sua identidade e Luíza Mahin, enquanto personagem mítico, se investe de um corpo que é construído via oralidade performatizada na literatura. ${ }^{11}$

Concluída a leitura da obra de Ana Maria Gonçalves, constatamos que os manuscritos encontrados pela personagem-autora não logram resolver o que permanece como ponto cego, esse desencontro, encenado na relação entre filho e mãe, via figura de Luíza Mahin. Nesse aspecto, o âmbito do ficcional replica uma indeterminação que tem lastro no presente vivido pela autora Ana Maria Gonçalves e pelos leitores da obra, movimento este que, por sua vez, também coloca tais corpos, da autora e dos leitores, em evidência. As cartas analisadas aqui atravessam esses corpos e constituem sujeitos que, como tantos outros integrantes da diáspora negra, ao verem-se forçosamente arrancados de suas terras, colocam em ação processos de "deslocamento, substituição, ressemantização, saturando os vazios e as cavidades originadas pelas perdas", como bem descreveu Leda Maria Martins (1997, p. 74). Da encruzilhada entre literatura e história surgem, assim, registros que se perfazem pela falta e tentam elaborar as perdas individuais, mas, a partir delas, o percurso de toda uma comunidade.

\section{Referências}

Costa, Luana Antunes. Traços do chão, tramas do mundo: representações do político de Mia Couto e Patrick Chamoiseau. Tese (Doutorado em Letras) - Universidade de São Paulo, São Paulo, 2014.

Ferreira, Ligia Fonseca (Org.). Luiz Gama por Luiz Gama: carta a Lúcio Mendonça. Teresa, São Paulo, n. 8/9, p. 300-321, 2008.

Ferreira, Ligia Fonseca (Org.). Com a palavra, Luiz Gama. Poemas, artigos, cartas, máximas. São Paulo: Imprensa Oficial do Estado de São Paulo, 2011.

11 Em determinado sentido, Luíza Mahin permanece viva, como mito, também por não ter tido seu corpo localizado e documentado pela História, e Luiz Gama, cujo corpo morto foi descrito num belíssimo texto de Raul Pompéia, é alçado, no texto desse autor, a uma condição de imagem épica, como é possível ler no seguinte fragmento: "Na sala da frente estava o corpo [...]. Lá estava sobre duas mesas aproximadas um grande cadáver, reto e fixo, as duas mãos rijamente cruzadas sobre um peito largo, trajado de negro, coberto a meio corpo por um pobre lençol grosseiro. O perfil do rosto alteava um pedaço de pano em firas saliências [...]. Levantava-se o lenço e via-se um belo semblante tranquilo como a noite do túmulo, ligeiramente alborizado pelo congelamento do sangue, dois olhos cruelmente cerrados para sempre sobre as mais suaves estrelas de bondade e de esperança, dois lábios colados como as pálpebras, selados por um ligeiro sorriso irônico sobre as mais ternas consolações de um largo coração. Impressionava a serenidade majestosa daquele morto. Sem aquele sorriso queixoso, que espiava por um canto dos lábios, fora a efígie de um Cristo. - Parece uma imagem, diziam [...]. Estive a olhar longamente para aquela estátua tombada [...]. Do interior da casa, chegava como em lufadas de alegria o gorjeio de muitos passarinhos" (PoMPÉIA, 1882/2011). 
FUNCEB - FundaçÃo Cultural do Estado da BAhia. Legislação da Província da Bahia sobre o negro: 1835-1888. Salvador: FUNCEB, 1996.

Gama, Luiz. Carta a Lúcio de Mendonça, 25/o7/188o. In: Ferreira, Ligia Fonseca (Org.). Com a palavra, Luiz Gama. Poemas, artigos, cartas, máximas. São Paulo: Imprensa Oficial do Estado de São Paulo, 2011. p. 199.

GonçAlves, Aline Najara da Silva. Luíza Mahin entre a ficção e a história. Dissertação (Mestrado em Estudo de Linguagens) - Universidade Federal da Bahia, Salvador, 2010.

GonçAlves, Ana Maria. Um defeito de cor. Rio de Janeiro: Record, 2006.

GonçALves, Ana Maria. Da narração histórica à ficcional: o processo de construção de Um defeito de cor, segundo Ana Maria Gonçalves: entrevista com Cristiane Cortês no dia 21 de julho de 2009, Belo Horizonte (MG). In: Duarte, Constância Lima; Duarte, Eduardo de Assis; Alexandre, Marcos Antônio (Org.). Falas do outro: literatura, gênero e etnicidade. Belo Horizonte: Nandyala, 2010.

Lima, Dulcilei da Conceição. Desvendando Luiza Mahin: um mito libertário no cerne do feminismo negro. Dissertação (Mestrado em Educação, Arte e História da Cultura) - Universidade Presbiteriana Mackenzie, São Paulo, 2011.

Martins, Leda Maria. Afrografias da memória: o reinado do Rosário no Jatobá. São Paulo: Perspectiva; Belo Horizonte: Mazza, 1997.

Miranda, Wander Melo. Corpos escritos: Graciliano Ramos e Silviano Santiago. São Paulo: Editora da USP, 2009.

OliveIrA, Klebson. Negros e escrita no Brasil do século XIX: sócio-história, edição filológica de documentos e estudo linguístico. Tese (Doutorado em Letras) - Universidade Federal da Bahia, Salvador, 2005.

Oliveira, Sílvio Roberto dos Santos. Gamacopéia: ficções sobre o poeta Luiz Gama. Tese (Doutorado em Teoria e História Literária) - Universidade Estadual de Campinas, Campinas, 2004 .

PompéIA, Raul. Última página da vida de um grande homem. Gazeta de Notícias, 10 de setembro de 1882. In: Ferreira, Ligia Fonseca (Org.). Com a palavra, Luiz Gama. Poemas, artigos, cartas, máximas. São Paulo: Imprensa Oficial do Estado de São Paulo, 2011.

ReIs, João José. Rebelião escrava no Brasil: a história do levante dos malês em 1835 . São Paulo: Companhia das Letras, 2003.

SLENES, Robert Wayne. Na senzala, uma flor: esperanças e recordações na formação da família escrava. Brasil Sudeste, século XIX. Campinas: Editora da Unicamp, 2011. 
Wissenbach. Maria Cristina Cortês. Teodora Dias da Cunha: construindo um lugar para si no mundo da escrita e da escravidão. In: CoRTÊs, Giovana Xavier da Conceição; Farias, Juliana Barreto; Gomes, Flávio dos Santos (Org.). Mulheres negras no Brasil escravista e do pós-emancipação. São Paulo: Selo Negro, 2012.

Recebido em 3 de março de 2018.

Aprovado em 15 de junho de 2018.

\section{Resumo/Abstract/Resumen}

\section{Luíza Mahin e Luiz Gama: escravidão e (auto)ficção numa correspondência} interceptada

\section{Fabiana Carneiro da Silva}

$O$ artigo retoma a significância do gênero carta no contexto escravista brasileiro para, a partir dos desdobramentos dessa reflexão, analisar comparativamente o romance, publicado em 2006, Um defeito de cor, que, em um de seus sentidos de leitura, performatiza uma carta de Luíza Mahin ao seu filho desaparecido, Luiz Gama; e a carta escrita pelo poeta Luiz Gama, em 1880, na qual surge pela primeira vez na discursividade do país o nome de Luíza Mahin, identificada como a mãe desaparecida de Gama. Diante de um contexto de violentas coerções, as possibilidades de uma "escrita do eu" pelos africanos e seus descendentes no Brasil vinculam-se, assim, a procedimentos que se fundamentam na suplementaridade entre a literatura e a história.

Palavras-chave: escrita do eu, escravidão, Um defeito de cor, Luíza Mahin, Luiz Gama.

\section{Luíza Mahin and Luiz Gama: slavery and (self)fiction in an intercepted correspondence}

\section{Fabiana Carneiro da Silva}

The article reaffirms the significance of the letter genre in the context of Brazilian slavery in order to analyze comparatively the novel, published in 2006, Um defeito de cor, which in one of its reading senses performatizes a letter from Luíza Mahin to her missing son Luiz Gama; and the letter written by the poet Luiz Gama in 1880, in which Luíza Mahin, identified as the missing mother of Gama, appears for the first time in the country's discourse. In the face of a context of violent coercion, the possibilities of a "writing of the self" by Africans and their descendants in Brazil are thus linked to procedures that are based on the supplementarity between literature and history. 
Keywords: writing of the self, slavery, Um defeito de cor, Luíza Mahin, Luiz Gama.

Luíza Mahin y Luiz Gama: esclavitud y (auto)ficción en una correspondencia interceptada

\section{Fabiana Carneiro da Silva}

El artículo retoma la significación del género carta en el contexto esclavista brasileño para, a partir de los desdoblamientos de esa reflexión, analizar comparativamente la novela Um defeito de cor, publicada en 2006, que en uno de sus sentidos de lectura performatiza una carta de Luíza Mahin a su hijo desaparecido, Luiz Gama, y la carta escrita por el poeta Luiz Gama, en 188o, en la que surge por primera vez en la discursividad del país el nombre de Luíza Mahin, identificada como la madre desaparecida de Gama. Ante un contexto de violentas coerciones, las posibilidades de una "escritura del yo"por los africanos y sus descendientes en Brasil se vinculan, así, a procedimientos que se fundamentan en la suplementaridad entre Literatura e Historia.

Palabras clave: escritura del yo, esclavitud, Um defeito de cor, Luíza Mahin, Luiz Gama. 